\title{
Tipos de conjugalidade e sexualidade na transição para a parentalidade de mulheres de classe média de Salvador, Bahia
}

\section{Types of conjugality and sexuality in their transition to parenting in medium class women from of Salvador, Bahia}

\author{
J uliana Orrico Viana Vilar* \\ Universidade Católica do Salvador - UCSAL, Salvador, Bahia, Brasil \\ Elaine Pedreira Rabinovich** \\ Universidade Católica do Salvador - UCSAL, Salvador, Bahia, Brasil
}

\begin{abstract}
RESUMO
Este trabalho estudou a dimensão da sexualidade do casal na transição para a parentalidade, tendo a tipologia de Aboim (2006) como base teórica de análise. Utilizou o método qualitativo de análise de conteúdo. Foram realizadas três entrevistas presenciais e três por email com mulheres de classe média que tiveram filhos recentemente, não havendo diferenças importantes entre os dois modos de abordagem. Cinco entrevistadas pertencentes aos perfis de Companheirismo Apaixonado e Amor de Alternância, onde os parceiros dão importância à sexualidade, relataram que o nascimento de seus filhos transformou a conjugalidade e a rotina, porém com melhorias neste relacionamento. Em Companheirismo em Construção onde a sexualidade não é vista com importância, a chegada do primeiro filho agravou a questão sexual do casal, o individualismo se contrapondo à individualidade. Sugere-se que os tipos descritos de conjugalidade podem estar associados a manejos diferenciais quanto à sexualidade na transição para a parentalidade.
\end{abstract}

Palavras chave: sexualidade, conjugalidade, parentalidade.

\begin{abstract}
This research studied the dimension of sexuality in the couple's transition to parenthood using Aboim's typology (2006) as the analytical theoretical basis. It was based on the qualitative method of content analysis. Interviews were conducted, three personally, three by mail, with six women from middle class, who have recently undergone this experience, with no significant differences between the two approaches. The five interviewees belonging to the profiles of Love Fellowship and Love Fellowship Toggle, where partners gave importance to sexuality, reported that the birth of their children has transformed the marital routine, bringing improvement to the relationship. In Fellowship Building, where sexuality is viewed with little importance, the arrival of the first child aggravated sexual troubles of the couple, bringing individualism in opposition to individuality. It is suggested that the described types of couples may come to be associated with different management as to sexuality in the transition to parenting.
\end{abstract}


Keywords: sexuality, conjugality, parenthood.

\section{Introdução}

A contemporaneidade está marcada pelo acelerado ritmo de vida, onde mulher e homem assumem diversos papeis e se dividem entre múltiplas funções. Nesse contexto, a conjugalidade assume um aspecto paradoxal onde os casais desejam ter uma vida conjugal valorizando o sentimento em detrimento do vínculo institucional (Diniz, 2009). Ocorre, também, uma busca por alto desempenho sexual, retrato de uma época marcada pela exposição exacerbada da sexualidade, com fácil acesso a elementos de cunho sexual, sejam na mídia, na literatura ou mesmo na forma de produtos sexuais ofertados em inúmeras sex shops. Dentro desse quadro, muitos casais fazem a transição para a parentalidade em que mulheres e homens se transformam em pais e mães, e igualmente suas vidas se transformam. O casal, ao aprender a incluir um novo membro na família, adquire uma nova configuração de sua vida conjugal. No entanto, pode-se levantar questões decorrentes desta transição da conjugalidade à parentalidade: quanto tempo levarão os casais, pais de primeira viagem, para se acostumarem à nova mudança de ritmo de vida? Como lidarão com a diminuição do tempo para o casal? E, em relação ao trabalho feminino externo à casa, como será realizada a adaptação frente às novas tarefas e desafios? Como a mulher lida com a sua inquietação de voltar à antiga forma física e do receio da perda de seu poder de sedução? E a questão da amamentação em relação a seios eróticos hoje intumescidos de leite? Como esta mulher lida com a sexualidade? Como o homem responde a esta nova mulher? Como os casais contemporâneos estão lidando com a sua sexualidade após o primeiro filho? Estas inquietações são a origem do presente trabalho, que buscou compreender a dinâmica da sexualidade do casal após o nascimento do primeiro filho.

Muitas vezes, a chegada de um filho faz com que a mãe sinta-se ignorada e isolada, sobrecarregada ante a maior complexidade das tarefas e relacionamentos. Os esposos, por sua vez, tentam ser bons maridos, pais e trabalhadores e acabam interpretando a aparente falta de interesse de suas esposas como uma rejeição, ou deixam de perceber o exaustivo trabalho que elas realizam. Ambos acham que não há um reconhecimento de seu valor pelo outro (Carter \& Mcgoldrick, 1995). I gualmente Magagnin et al. (2003), investigando longitudinalmente a parentalidade em relação ao ajustamento diádico e à satisfação conjugal de 41 casais primíparos, corrobora as dificuldades relatadas durante este período.

A comunicação do casal perde a fluidez, apresentando ruídos, e a vida sexual do casal pode sofrer as conseqüências desta falta de 
comunicação, entrando em crise. Apontando esta conexão, Pasini (1995), que dirige um serviço em Genebra de assistência familiar em dois centros separados - um de Terapia de Casal e outro de Sexologia clínica - verificou que suas demandas estão interligadas: os casais que não conseguem se comunicar são os que apresentam questões ligadas à vida sexual do casal.

Nichilo (1995) considera que a comunicação, em muitos casais contemporâneos, apresenta ruídos. O homem e a mulher, para evitar um conflito, acabam se isolando. E como fica a vida sexual deste casal?

Menezes e Lopes (2007) analisaram a relação conjugal durante a transição para a parentalidade concluindo que esta é uma das maiores mudanças do sistema familiar, apontando que o nascimento do primogênito é a "primeira experiência de parentalidade vivida pelo casal" (p.83). Concluíram também sobre a importância da comunicação nesta transição.

Até há pouco tempo, aproximadamente quatro ou cinco décadas, falar de sexo no Brasil ainda era um tabu. A virgindade era considerada como um valor para a mulher a ser mantida até o casamento. Quando deixavam de ser virgens, perdiam seu valor como esposas, e ganhavam o rótulo de mulheres fáceis. As mulheres não faziam exigências sexuais a seus maridos; portanto, se estes falhassem era um assunto velado. Muitas delas acabavam não tendo prazer sexual, fazendo sexo só por obrigação (Diehl, 2002).

Para Diehl (2002), os homens não eram rotulados caso perdessem sua virgindade antes do casamento. $\mathrm{Na}$ verdade, os mesmos deveriam ensinar as suas esposas castas e santas o ato sexual. Assim, eles normalmente iniciavam a sua atividade sexual com as prostitutas, que eram consideradas como professoras do sexo. "A exigência de fidelidade traduzida, em parte, pela virgindade, dava aos homens a idéia, mesmo que ilusória, da exclusividade em relação à sexualidade e à paternidade" (Diehl, 2002, p. 141).

Ao longo do tempo, a vida sexual se tornou mais livre e liberal. A perda da virgindade passou a ser, tanto para homens quanto para mulheres, entre amigos ou namorados. Assim, trouxe mais intimidade e afetividade nas relações para ambos os sexos (Costa, 1986).

De acordo com Diehl (2002), as mulheres passaram a exigir dos homens tanto em nível conjugal (afeto, atenção, amor e carinho) quanto em nível de satisfação sexual. Neste segundo item, elas esperam que seus parceiros possam levá-las ao orgasmo. Se, durante mais de quatro séculos, os casamentos não se faziam de acordo com a atração sexual recíproca, atualmente o amor e o prazer tornaram-se obrigatórios, tendo-se imposto a ditadura do orgasmo (Del Priore, 2005). Assim, o homem atual sente-se inseguro quanto à postura da mulher contemporânea, que se mostra mais segura e 
independente emocional e financeiramente (Diehl, 2002).

Mesmo com tais mudanças acontecendo ao longo da história, o sexo ainda é um tema que tem limitações e preconceitos sociais. Com o advento da pós-modernidade, homens e mulheres passaram a se exigir e exigir do parceiro um sexo "perfeito". Desta forma, o que era para ser uma fonte de prazer passou a ser também um fator estressor (Diehl, 2002; Del Priori, 2005).

Três autoras norte-americanas, Cockrell, O'Neill e Stone (2009), a partir de suas experiências pessoais, entrevistaram homens e mulheres em algumas cidades dos Estados Unidos sobre o casal e os filhos. Um de seus capítulos versou sobre a vida sexual depois do primeiro filho. As autoras concluem que as mulheres vêem o sexo como obrigação após ter o filho, e o homem tem dele necessidade, sendo este a forma que encontra de comunicação com a mulher. Assim, sugerem que a mulher deve se esforçar para fazer sexo mesmo sem vontade e praticar sexo oral, dado este poder ser realizado rapidamente. Deste modo, este estudo enfatiza a dificuldade existente no relacionamento do casal após o nascimento do filho e sua incidência na sua vida sexual.

As formas atuais de relacionamento, em decorrência de várias mudanças sociais e culturais, têm como estrutura os princípios democráticos e a igualdade. Para Giddens (1993), estes novos arranjos de relacionamentos são influenciados por três categorias: a sexualidade plástica, o relacionamento puro e o amor confluente. Para se entender as transformações da intimidade, estas categorias são fundamentais (Feres-Carneiro, 2011).

A sexualidade plástica se caracterizaria por não ser ligada às necessidades de reprodução. Esta se propagou com os métodos contraceptivos e as tecnologias relacionadas à reprodução nos laboratórios. Esta sexualidade foi gerada em decorrência dos movimentos feministas que aconteceram no final do século XX. A partir dos anos 60, a mulher passa a reivindicar seus direitos, como 0 do prazer sexual (Feres-Carneiro, 2011).

A união de parceiros se dá, via de regra, com a expectativa de um relacionamento sexual mais contínuo. De tal forma que a lei, nos casos em que a união de corpos não se realiza, permite a anulação do casamento. Faz-se importante considerar também que, com o passar do tempo, a relação sexual passou por mudanças que a levaram de um ato meramente reprodutivo, a uma troca não só de amor e afeto, mas, também, de sensualidade e prazer. Os casais, assim, parecem, cada vez mais estar propensos a exigir relacionamentos sexuais de qualidade em seus casamentos, além de não abrirem mão de todo o prazer que o ato sexual pode oferecer (Falcke, Diehl, Wagner, 2002).

Feres-Carneiro (2011) chegou à conclusão, face pesquisas e estudos na área conjugal, que a vida sexual do casal sofre forte influência 
ante o nascimento de um filho assim como ante as excessivas cargas de trabalho dos cônjuges. Tantos homens quanto mulheres relataram uma redução da atividade sexual devido a estas questões.

Como ocorrerá esta transição em cada casal específico? Uma das marcas do movimento de modernização das sociedades ocidentais é a construção social do sentimento amoroso, resultado da modernidade onde a individualização das famílias se torna cada vez mais intensa, refletindo a mudança na situação das mulheres, a variedade dos tipos de famílias, a reconstrução do ciclo de vida tradicional. Dentro deste âmbito, o individuo se vê dividido entre a liberdade individual e as gratificações amorosas de uma vida a dois (Aboim, 2006).

Pode-se pensar que o sentimento amoroso da modernidade seria conseqüência da individualização, que colocou a conjugalidade num grau de maior importância. Assim, como o indivíduo se vê dividido, o casal contemporâneo ver-se-ia dividido entre um ideal de fusão afetiva, onde existem sonhos de felicidade pessoal, e o investimento na realização individual (Aboim, 2006).

Neste estudo, estamos nos apoiando para a sua análise na teoria desenvolvida por Aboim. A Prof. Dra. Sofia Aboim é membro participante do Instituto de Ciências Sociais da Universidade de Lisboa - ICS/Portugal, Instituto este que tem se distinguido internacionalmente pela qualidade e extensão de estudos que, no campo das Ciências Sociais, enfatizam aspectos relacionados à dinâmica da família contemporânea, considerando seus vários estratos sócio-econômicos, assim como diferenças culturais e históricas. Devido às características destes estudos, eles podem ser aplicados à realidade brasileira. Por ocasião da realização do presente estudo, ainda não haviam sido relacionados os tipos de conjugalidade à vida sexual do casal, mas apontaram a intenção de realizá-los. E, de fato, em 2013, esta autora lançou, em Portugal, um livro denominado: "A sexualidade dos portugueses".

Para Aboim (2006), citando Neyrand (2002), o imaginário do casal é marcado por tendências aparentemente contraditórias, configurando o que alguns entendem por paradoxo conjugal contemporâneo. Neste paradoxo, os casais se baseiam muito mais no afeto do que nos aspectos patrimoniais, econômicos ou genealógicos, antes essenciais na sua institucionalização. Por outro lado, a individualidade ganhou muita importância, tornando-se independente do casal e da família.

Para Singly (2000), os indivíduos querem ser livres em conjunto: desejam ter uma vida conjugal (ser com o outro), da qual depende sobremaneira a construção das suas identidades, e uma vida pessoal autônoma (ser a sós). O autor utiliza mesmo o termo dupla vida para aludir a este paradoxo do individualismo contemporâneo (Aboim, 2006, p. 802).

Para Abboim (2006), o casal pode se formar a partir da fusão ou da autonomia. Na fusão, a primazia é dada ao nós, unindo recursos, 
tempos, espaços e até identidades. Já na autonomia, é a preferência do eu, onde tenta se preservar as diferenças, particularidade e espaço-tempo de cada um, sendo que entre um e outro muitas conjugalidades são possíveis. Diante disso, Aboim (2006) propõe uma hipótese em seu artigo Conjugalidade, afetos e formas de autonomia individual, nos seguintes termos: considerando as conjugalidades atuais formadas por afetos e também por obrigações e rotinas do cotidiano, quais seriam as possíveis articulações entre orientações amorosas (a paixão, o amor, a amizade, o companheirismo) e interações conjugais? A autora traz, deste modo, a articulação entre a sentimentalização da vida do casal e a individualização, identificando formas variadas de construção feminina face ao nós casal, ligando-as às orientações amorosas veiculadas pelas mulheres. Investigando a autonomia feminina na conjugalidade, a autora procurou saber o que une o casal e o que o separa em seguida. No primeiro caso, privilegiou a área de fusão conjugal (intimidade afetiva, produção da vida material, concretização do projeto familiar), as relações de gênero do casal (complementaridade de papeis, procura de igualdade), ou ainda o peso dado ao nós casal e ao nós família. Analisou a percepção da mulher sobre si mesma, o significado atribuído à profissão e o tipo de autonomia produzido dentro da conjugalidade (Aboim, 2006). Investigou os modos de integração do indivíduo no grupo (a autonomia e a fusão) e a natureza da relação entre o público e o privado (fechamento ou abertura ao mundo exterior).

Como uma vasta literatura sociológica demonstra, os primeiros anos de vida em comum e a transição para a parentalidade têm, na construção da relação conjugal, um enorme impacto, reorganizando posições de gênero, lógicas afetivas, fusões, autonomias, trabalho e lazer, em poucas palavras, as maneiras de fazer o quotidiano. (Aboim, 2006).

Aboim (2002) propõe tipos de conjugalidade. Três desses tipos pareceram importantes para a pesquisa em pauta: Companherismo de apaixonado, Amor de "alternância" e Companherismo em Construção. No primeiro tipo, companheirismo apaixonado, existe uma valorização da paixão em uma relação onde ocorre uma construção permanente, uma importância da sexualidade, uma procura de igualdade de gênero, fusão emocional, intimidade, comunicação, apoio. Aqui a autonomia feminina interior é mínima, apenas alguns pensamentos não são partilhados. A família é mais importante do que a profissão, mas a profissão também pode ser gratificante e realizadora, caso aconteça. Existe uma ausência de atividades individuais femininas. Para Aboim (2002), este casal se caracteriza por um nós casal/nós família, ou seja, por uma valorização da conjugalidade e da parentalidade, deixando de lado a individualidade, o eu. 
No segundo tipo, amor de "alternância", os indivíduos preservam a sua autonomia, pois a própria construção de intimidade surge dependente da paridade e da negociação entre ambos os parceiros. Não se trata de uma tensão entre o individualismo e fusão amorosa, mas de uma intimidade baseada na independência pessoal, na igualdade e na gestão de diferentes pertenças e instâncias de realização do self. A relação amorosa conjugal é, por excelência, a alteridade valorizada.

No terceiro tipo, companheirismo em construção, as mulheres pensam que o "estar apaixonada" tem ainda hoje uma forte conotação fusional, ligando-se a autonomia pessoal à construção de formas de afetividade "amicais" que consideram menos intensas e, por isso, também menos exigentes em matéria de disponibilidade pessoal. Um companherismo visto como dinâmico, mutável, em constante renovação. Uma relação sempre em construção, onde a transformação do sentimento conjugal teve como contrapeso uma também progressiva individualização feminina, produzida, a dado momento do percurso conjugal, pela estratégica e conscientemente formulada de autonomia pessoal. Importa salientar que aqui o ideal feminino não é apenas ser mãe, apenas esposa ou profissional, mas sim uma combinatória equilibrada destes papeis, num mesmo nível de importância subjetiva. O desejo de ser perfeita em todas estas funções coloca uma carga de exigência muito pesada sobre a mulher. Portanto, a partir do exposto, pode-se indagar: Cada casal tem suas peculiaridades que lhe são próprias e sua maneira de "conjugar"? Como se organiza cada casal e quais ferramentas ele utiliza para lidar com a grande mudança que é a chegada do primeiro filho? O filho faz eclodir uma situação conjugal que já existia antes da sua chegada? Como se define a sexualidade de cada casal face à tipologia de Aboim (2002)? Outras mudanças poderiam ocorrer e o casal mudar radicalmente também a sua maneira de se relacionar e viver a sexualidade, não conectadas à chegada do filho?

A partir das considerações acima, tomamos por objeto de estudo a transição da conjugalidade para a parentalidade, focalizando a vida sexual do casal, utilizando as definições de Aboim (2002) com as possíveis repercussões na sexualidade ante a parentalidade. Assim, este trabalho teve como objetivo geral estudar a dimensão da sexualidade do casal na passagem da conjugalidade para a parentalidade e, como objetivos específicos, identificar as implicações da chegada do primeiro filho na vida sexual do casal atual segundo a ótica da mulher e as possíveis relações entre tipos de conjugalidade e sexualidade na transição para a parentalidade.

\section{Método}


O desenho da investigação utilizou o método qualitativo de análise de conteúdo. A amostra intencional foi constituída por seis mulheres, com idades entre 27-37 anos, de nível educacional superior (graduação e pós-graduação), classificados sócio-demograficamente como classe média, residentes na cidade de Salvador, com o filho primogênito de idade de 6 meses- 3 anos. Seus companheiros apresentaram idades de 29 a 41 anos e tinham escolaridade no nível superior completo. As profissões, tanto das mulheres quanto dos homens, foram variadas.

Os dados foram coletados através de entrevistas individuais, com roteiros semi-estruturados. Três entrevistas foram realizadas de modo presencial e três entrevistas foram realizadas on-line, por meio de e-mail. A entrevista obedeceu ao seguinte roteiro: sexo; idade; ocupação; Você considera que contribui para a esfera domestica? De que forma? Acha o suficiente esta contribuição? Por que?; Você considera que seu parceiro(a) contribui para a esfera domestica? De que forma? Acha o suficiente esta contribuição? Por que?; Tempo de namoro; Tempo de casamento; A decisão de ter um filho foi de um ou dos dois? Conte como aconteceu; Quais as mudanças que o período gravídico trouxe para a vida do casal? Você utiliza algum método anticoncepcional após o parto? Caso sua resposta seja sim, qual tipo? O mesmo lhe causa alguma alteração física? Você amamenta ou amamentou o seu filho via leite materno? Se sim, como você se sente ou se sentia, ao amamentar? O que mudou na vida do casal após a chegada do primeiro filho? Se puder mensurar quanto é sua dedicação ao seu filho numa escala de 0 a 10? Acha que precisa mudar? Se puder mensurar quanto é a dedicação de seu parceiro(a) ao filho de vocês numa escala de 0 a 10? Acha que precisa mudar? Como era a vida sexual do casal antes do primeiro filho, em termo de satisfação? Justifique. Como ficou esta satisfação com a chegada deste filho? Justifique. Caso tenha piorado, o que você considera que precisa acontecer para reverter esta situação?

$\mathrm{O}$ acesso às participantes ocorreu pela técnica da "Bola de Neve" em que uma participante indica a seguinte. Este procedimento é indicado devido à pesquisa levantar questões referidas à intimidade da pessoa e à dificuldade de acessar participantes devido ao conteúdo das entrevistas.

De acordo com Flick (2009), a entrevista qualitativa não escapa aos efeitos da revolução digital e tecnológica do início do século XXI. Os computadores são utilizados para se analisar dados qualitativos; Mp4 são utilizados para gravar as entrevistas; a internet e seus aplicativos, como e-mails, são utilizados para entrevistas, busca de literatura cientifica e publicar resultados.

Além disso, a internet faz parte hoje do cotidiano das pessoas. Muitas atividades laborais têm utilizado a internet para as suas manobras. As pessoas utilizam os e-mails e salas de redes sociais para se 
comunicar. Não são todas as pessoas que têm acesso a este aplicativo, mas na presente pesquisa, o grupo selecionado de classe media alta tem acesso e utiliza a mesma na sua vida cotidiana. Algumas das entrevistadas inclusive, ao serem convidadas a participar da pesquisa, solicitaram ser por e-mail porque se sentiriam mais à vontade para falar livremente e sentiam que "falariam" mais do que ao vivo.

Porém, na prática, a entrevista on-line é organizada de uma forma diferente da entrevista ao vivo. Numa pesquisa semiestruturada, o usual é realizar um grupo de perguntas levadas à pessoa que será entrevistada, sendo um caminho pelo qual o entrevistador se norteará, podendo modificar as perguntas ao longo das respostas. $\mathrm{Na}$ pesquisa on-line, pode-se fazer um questionário, distribuir e esperar as repostas on-line. Mas este modo de proceder fugiria do objetivo do presente estudo e da pesquisa qualitativa semiestruturada (Flick, 2009).

Assim, Flick (2009), sugere que se planeje a coleta de dados de uma forma mais interativa, enviando uma primeira pergunta e, depois de respondida, enviando as subsequentes, sendo realizadas várias trocas de emails no modo aproximado de um "diálogo". A entrevista on-line é um modo de realizar a pesquisa qualitativa no contexto do trabalho de pesquisa na internet. Pode ser muito vantajosa se a ideia for integrar aos estudos participantes que não sejam facilmente acessíveis, por viverem longe ou por não desejarem falar com um estranho (sobre um tópico possivelmente sensível). A pesquisa online pode também permitir a seus participantes o anonimato, o que pode ser uma vantagem. A entrevista online produz dados já disponíveis na forma de textos, o que permite a omissão da demorada etapa da transcrição das entrevistas (Flick, 2009, p. 243).

Dessa forma, na presente pesquisa, o método da pesquisa qualitativa online trouxe vantagens como: o acesso a participantes de diferentes localidades num mesmo tempo; a facilidade de obter mais dados conforme o estudo fosse evoluindo e um espaço de total privacidade onde as entrevistadas se sentissem livres e confiantes para falar, já que se trata de um espaço em que elas já estão habituadas no seu cotidiano.

Após os contatos iniciais por telefone, em que foi explicado sucintamente o objetivo do estudo, entrevistas foram agendadas de acordo com a possibilidade oferecida pela interlocutora. Antes da entrevista, esta leu e assinou o Termo de Comprometimento Livre e Esclarecido.

A análise buscou responder aos itens alcançados como objetivos secundários por meio de análise de conteúdo (Flick, 2009). Devido à técnica Bola de Neve ter sido o modo de acessar as participantes, alguns dados pessoais foram alterados para que as entrevistadas não fossem identificadas, preservando a sua privacidade. 


\section{Resultados e discussão}

Neste item, será apresentada a análise das entrevistas na forma de estudos de caso, procurando evidenciar a história conjugal em relação à sexualidade e parentalidade segundo o relato de cada uma das participantes. Esta análise se apóia na tipologia de Aboim (2004). Por questões práticas, será exposto apenas um caso de cada tipo.

\subsection{Companheirismo em construção}

F e B namoraram nove anos e casaram há três anos. Conheceram-se, tornaram-se amigos e só começaram a namorar depois de um tempo. Terminaram o relacionamento e voltaram algumas vezes, passando períodos de tempo morando em cidades diferentes. A entrevistada conta que considera o seu relacionamento conturbado, e deve isso ao fato de tanto ela quantos seu esposo terem personalidades muito fortes, e devido a seu marido ser filho único de uma mãe que dedicou toda a sua vida a ele. Com dois anos de casados, tiveram o primeiro filho. Não considera a sua relação ideal, mas se empenham em resolver as diferenças. Antes da gestação, tinham uma vida social muito ativa. Os dois têm uma vida profissional intensa, trabalhando o dia todo. A esposa gosta de manter a sua independência. Sente que o marido não pensa como ela quanto aos cuidados com o filho, sentindo que ele se doa menos do que ela. Em relação à atividade sexual, a frequência era pouca antes do bebê nascer, diminuindo mais ainda. A entrevistada considera ter um filho como um grande desafio na vida do casal e pessoal. São um casal que dividem as tarefas, e os dois têm uma vida individual muito bem demarcada.

Aqui se pode perceber um casal, de acordo com a tipologia de Aboim (2004), como companheirismo em construção. A entrevistada marca o seu território dentro da relação. Sua profissão recebe grande atenção, tanto que, na gravidez, houve um momento em que seu esposo pede para ela se afastar com receio de trazer alguma consequência para o bebê. Depois de verificar que nada aconteceria, continua trabalhando e diz: "ele ficou muito preocupado com minhas atividades laborais na gravidez (...) foi estressante(...) tinha responsabilidades profissionais e não poderia abrir mão do meu trabalho por conta da gravidez".

Não há um romantismo no casamento, e pouca fusão, como se pode ver com a fala: "Ainda hoje encontramos dificuldades em mantermos uma convivência harmônica, não considero nossa relação algo ideal (...)".

Levanta-se a hipótese de que a chegada de um filho só fez eclodir uma situação que já existia. Os dois já tinham vidas independentes e 
uma busca por igualdade de gêneros. Os dois demonstram que precisam delimitar seus espaços. Com a chegada do filho, a mulher não tem outra opção a não ser a de se dedicar a esta criança, diminuindo o seu tempo para si e para o outro, como se observa na fala:

“(...) diria que o que mais mudou foi a atenção que cada um de nós passou a receber do outro. Sinto que um filho desperta muito mais amor nos seus pais e que a relação do casal passa a ficar em segundo plano... No nosso caso, existe uma distinção de como cada um vê o papel de um pai e de uma mãe... confesso que abri mão de minhas atividades extra trabalho para me dedicar ao nosso filho e que preciso trazer mais equilíbrio para a minha vida. Ele também abriu mão, porém consegue manter seus compromissos sociais à noite com seus amigos."

Portanto, mesmo com a "igualdade entre gêneros" manifestada na gravidez, por exemplo, quando a esposa continua a trabalhar mesmo contra o desejo de seu marido, após o nascimento do filho, ela parece assumir uma posição mais tradicional feminina, dedicando-se ao filho e em trazer harmonia ao lar.

\subsection{Amor de alternância}

"Antes da gravidez tínhamos cumplicidade, mais depois ficamos mais unidos, como uma família. Tudo é decidido junto, sem individualismo". Esta fala exemplifica que se trata de um casal classificado para Aboim (2004) como "Amor de alternância". Onde existe amizade e ajuda mútua dentro da conjugalidade, uma relação de companheirismo, mas também de paixão e desejo. 0 sexo tem importância aqui. "A relação sexual não mudou em si, acho que mudou temporalmente, pois com as crianças o sexo passa a ter hora marcada(...) Mas o tesão continua o mesmo".

Neste tipo de conjugalidade, a mulher se divide entre várias funções: trabalho, casa, filhos, família e a relação conjugal. A mulher tem autonomia nas rotinas e na intimidade.

Como neste tipo de relação existe diálogo, interesses em comum, cumplicidade, sentimento, forte territorialização das instâncias privilegiadas do eu, casal, família realização profissional e bem estar pessoal, a par do investimento fusional, abertura ao exterior, sociabilidade forte, características que fazem com que este tipo de casal se adapte ao nascimento da criança mantendo a relação conjugal, sentindo-se mais unidos. "O trabalho mudou muito, pois eu tive que assumir todas as funções de cuidado direto dos meninos, mudando muito minha rotina. Como temos a empresa, também tive 
que assumir funções que antes não assumia".

Pode-se perceber que nem o esposo nem a esposa perdem seu espaço ou deixam de ter interesse no outro. Lidam com o nascimento encarando a nova realidade, mas entendendo que agora, além dos papeis de filhos e de marido e mulher, têm também a nova função de pais.

“Logo após o nascimento, nas primeiras semanas, a vida sexual era inexistente .... Aos poucos, a criança vai crescendo e você se acostuma com ela, com suas particularidades, com 0 trabalho que ela dá e seu corpo também volta ao normal o que me faz sentir mais mulher, mais desejada. Ai ocorre a mudança e seu marido passa a te atrair novamente, sentia vontade de estar com ele inicialmente, sair e fazer coisas banais e depois vem o desejo sexual mesmo. A relação ficou boa, o sexo fica tão bom ou melhor porque você tem uma relação ainda mais forte, como se o amor tivesse crescido. Volta tudo ao normal, parece que não vai voltar mais volta".

\subsection{Companheirismo apaixonado}

"Tivemos uma história bem romântica". Assim se define este casal pela visão da esposa. Começaram a namorar ainda na adolescência, "(...) com separações e reencontros cinematográficos $(. .$.$) ", voltando a$ se reencontrar na vida adulta já mais maduros. A entrevistada considera que são muito parecidos em vários aspectos : “(...)dizem que somos um casal que dança de tão encaixado(...)"

Neste caso claramente se trata de um casal classificado por Aboim (2004) de "Companheirismo Apaixonado", característico por uma identidade conjugalizada, presente em namoros muito jovens. Os membros do casal vão se conhecendo e formando as próprias identidades pela alteridade. Aqui, a paixão e atração são supervalorizados: “( ...) Bom, os momentos de paixão continuam indo e voltando... como casal foi muito gratificante ver que do nosso amor, geramos uma criança e que ela é fruto disso(...)"

O sentimento família é muito forte; de acordo com Aboim (2004), este casal dá ênfase ao "nós casal" e ao "nós família".

"Parece que o casamento só começou de fato depois que ele nasceu....Meu esposo sempre teve uma individualidade super bem resolvida. Eu só conheci de fato a individualidade com o casamento e foi uma ótima descoberta. A gravidez e o nascimento tiraram tempo, mas aprendemos a valorizar os momentos individuais e conseguimos ter esses momentos sempre, ainda bem! Nesse aspecto, o professor foi o casamento e foi muito tranquilo. Isso não mudou com a gravidez, só 
diminuiu a freqüência dos momentos dele".

Desta forma, para a mulher a família é mais importante do que a profissão, mas esta, caso aconteça, também pode ser gratificante.

“(...) bom, antes dele nós trabalhávamos muito( ...) estávamos sempre juntos e gostávamos de trabalhar juntos, sempre nos demos bem no trabalho. Perto de engravidar decidimos mudar totalmente a vida ... a grande mudança em termos de trabalho foi por decisões de vida, não pelas crianças, apesar delas serem minha motivação..."

Outra característica importante deste tipo de conjugalidade é a ausência de atividades individuais, pouco espaço para o "EU".

“(...) Na vida prática, mudou muito minha rotina, porque passei a me dedicar exclusivamente à criança, o que é muito gratificante, apesar de super cansativo. Não tive problemas com o fato de não trabalhar porque não gostava do meu trabalho e adoro a vida doméstica. Meu esposo ficou preocupado com esta escolha mas depois percebeu que eu estava feliz em ficar em casa...digo a todos que minha profissão é ser mãe. Adoro, leio todos os livros, brinco, ensino, vivo com meu filho. Minha vida própria é no horário da escola dele e a noite...".

Neste caso, o sexo tem muita importância:

“(...) Hoje, pelo tempo de convivência e a segurança inimaginável que filho traz para nossa relação, acho que o sexo fica cada vez mais aberto, curtido, sem medo nem expectativas. E não consigo imaginar isso sem as experiências e emoções que os filhos nos fazem passar... acho que o entrosamento e o companheirismo realmente melhoram nossa vida sexual ..."

A rotina é muito fusional, são parceiros de vida companheiros, característica deste tipo de conjugalidade:

“(...) A parceria e companheirismo atingiram um nível que eu nem conhecia depois da gravidez. Sempre fomos parceiros e melhores amigos, mas hoje temos uma vida totalmente interligada, interesses e projetos praticamente dependentes(...) nós gostamos e ficamos muito felizes com isso. ... certeza absoluta de que somos capaz de superar tudo juntos e isso é muito gostoso, tranquilizador..." 
Existe abertura à sociabilidade, porém o sentimento de “nós casal e "nós família" se mantém como prioridade.

“(...) Como casal, a grande diferença que noto é que depois dos filhos precisamos priorizar, para conseguir, momentos nossos, a sós, coisa que antes era natural, já que todo nosso tempo livre era nosso... nossa vida social é muito intensa e precisamos sempre fugir de convites para conseguir um jantar a dois, mas achamos isso importante e fazemos questão de ter esse momento de vez em quando ...".

\section{Ensaio de análise da relação entre tipo de conjugalidade e sexualidade na transição para a parentalidade}

Na presente pesquisa foi possível classificar as seis entrevistas em três tipos de conjugalidade: Companheirismo em construção, Companheirismo apaixonado e Amor de alternância, sendo que três casos se encaixaram em Amor de Alternância; dois casos em Companheirismo apaixonado e apenas um caso em Companheirismo em construção.

Nos três tipos de conjugalidade, a sexualidade continuou tendo a mesma importância. No tipo Companheirismo em construção, onde a sexualidade não tinha uma grande importância, continuou da mesma forma, diminuindo mais ainda a freqüência e o desejo. Já nos tipos Companheirismo Apaixonado e Amor de Alternância, em que o sexo já tinha grande importância, ganhou uma atenção maior ainda depois do nascimento do bebê. A freqüência das relações sexuais diminuiu por questões de tempo, disponibilidade e cansaço do casal, porém a satisfação sexual teve uma melhora considerável relatada pelas entrevistadas.

Pode-se concluir que, nos tipos de conjugalidade onde os parceiros dão importância à sexualidade e o relacionamento tem nesta um pilar, o nascimento de um filho, considerado um grande marco na vida de um casal, traz mudanças significativas nas suas vidas, porém não piora a sexualidade do casal. Ela se transforma, amadurecendo junto com a evolução do casal. As dificuldades, nestes tipos conjugais, trazem benefícios a longo tempo. As cinco entrevistadas que se encaixam nestes dois tipos de conjugalidade relataram que 0 nascimento de seus filhos trouxe muitas dificuldades, e transformou bastante a conjugalidade e a rotina, porém sentem-se mais felizes em seus casamentos, considerando-os mais fortes, tendo havido um aumento na sua admiração em relação a seus esposos, e uma satisfação sexual melhor do que antes do parto. 


\section{Considerações finais}

Este estudo entrevistou seis mulheres, mães recentes, três por meio de entrevistas realizadas presencialmente, três por meio da internet. $\mathrm{Na}$ investigação foi utilizado o método qualitativo de análise de conteúdo. De acordo com Flick (2009), a entrevista qualitativa não escapa aos efeitos da revolução digital e tecnológica. Poder utilizar os recursos de comunicação disponíveis na Internet permitiu que o acesso às entrevistadas, assim como o acesso a intimidade do casal, ocorresse mais facilmente.

Portanto, a primeira consideração final é de ordem metodológica, pois não houve diferenças importantes entre estes dois modos de abordagem. De fato, algumas mulheres declararam sentirem-se mais confortáveis utilizando um meio indireto para falar de assuntos íntimos, do que conversando diretamente com a entrevistadora.

Para minimizar as diferenças de resultado entre as entrevistas presenciais e as não-presenciais, foi necessário organizar as entrevistas on-line de forma mais interativa, mantendo o objetivo do presente estudo de realizar uma pesquisa qualitativa semiestruturada. As pesquisas, realizadas via e-mail, foram realizadas seguindo o modelo de um diálogo, com uma pergunta por vez. Feita a pergunta, aguardava-se a resposta, para só então enviar uma próxima pergunta, permitindo assim, que as perguntas fossem modificadas de acordo com as respostas recebidas.

Quanto aos objetivos traçados para o trabalho, no que diz respeito às implicações da chegada do primeiro filho na vida sexual do casal, segundo a ótica da mulher, pode-se concluir que nos tipos de conjugalidade (Companheirismo Apaixonado e Amor de Alternância) onde os parceiros dão importância à sexualidade e o relacionamento tem nesta um pilar, o nascimento de um filho, considerado um grande marco na vida de um casal, trouxe mudanças significativas nas suas vidas, porém não piorou a vida sexual do casal. As cinco entrevistadas que se encaixam nestes perfis de conjugalidade, relataram que o nascimento de seus filhos trouxe muitas dificuldades, e transformou bastante a conjugalidade e a rotina, porém sentem-se mais felizes em seus casamentos, considerando-os mais fortes, tendo havido um aumento na sua admiração em relação a seus esposos, e uma satisfação sexual melhor do que antes do parto. Portanto, a relação sexual se transforma, amadurecendo junto com a evolução do casal. As dificuldades, nestes tipos conjugais, trazem benefícios a longo tempo.

No tipo de conjugalidade onde a sexualidade não era vista com importância (Companheirismo em Construção), a chegada do primeiro filho agravou a questão sexual do casal, pois além da diminuição da frequência das relações, ocorreu ainda a diminuição do 
desejo sexual. Como a sexualidade e a comunicação do casal estão interligadas, devido à diminuição das relações sexuais, criou-se um abismo entre o casal, aumentando o sintoma de não comunicação, fazendo vir à tona uma crise conjugal. O casal, desta forma, com passar do tempo envolvido neste contexto, distanciou-se e começou a não se reconhecer mais um no outro. A alteridade deixa de existir. $O$ individualismo se contrapõe ao que deveria ser a individualidade.

Portanto, embora os casos sejam poucos, pode-se levantar a suposição de que os tipos de conjugalidade conforme Aboim (2006) podem vir a estar associados a manejos diferenciais quanto à sexualidade ante a parentalidade e se adéquam à realidade brasileira como fontes potenciais de futuras pesquisas.

Apesar de viverem em um período histórico em que há fácil acesso a elementos de cunho sexual, seja na mídia, na literatura ou mesmo na forma de produtos sexuais ofertados em inúmeras sex shops, as entrevistadas mostraram-se inibidas e receosas para falarem de sua vida sexual, algumas delas preferindo utilizar o e-mail para "falar" de sua intimidade sexual, sinal de que, apesar de viverem em um período de esclarecimento sexual e alta erotização, não se sentem confortáveis para falar abertamente sobre o tema. Em sua intimidade ainda existem tabus relacionados ao assunto. Essa "dificuldade" em retratar a intimidade pode deixar lacunas nos relatos. Estas conclusões vão ao encontro às de Bozon (1995) de que "a liberação dos costumes" (p.132), o desenvolvimento da contracepção e as transformações contemporâneas da condição das mulheres não transformaram de modo profundo as representações neste domínio.

Provavelmente devido a isto, embora muitos trabalhos estejam disponíveis sobre a conjugalidade ou parentalidade ou sexualidade, pouco foi encontrado sobre a sexualidade em sua relação com a conjugalidade e com a parentalidade.

Um aspecto importante a ser considerado em trabalhos futuros é a contribuição do ponto de vista masculino para a pesquisa. Relatos das questões que assolam o universo masculino durante essa fase da vida do casal são importantes para que uma visão mais holística do processo seja possível.

\section{Referências}

Aboim, S. \& Wall, K. (2002). Tipos de Família em Portugal: Interacções, valores, contextos. Análise Social, 37(163), 475-506.

Aboim, S. (2004, maio). Emoções e rotinas: a construção da autonomia da vida conjugal. Actas dos ateliers do $\mathrm{V}$ congresso de sociologia, Minho, Portugal, 146-155.

Aboim, S. (2006). Conjugalidades em mudança. Percursos e dinâmicas da vida a dois. Lisboa: Imprensa de Ciências Sociais. 
Bozon, M. (1995). Amor, sexualidade e relações sociais de sexo na França contemporânea. Estudos Feministas, 3(1), 122-135.

Carter, B. \& Macgoldrick, M. (1995). As mudanças no ciclo de vida familiar: uma estrutura para a terapia familiar. In: B. Carter \& M. Macgoldrick (Orgs.). As mudanças no ciclo de vida familiar. pp. 7-29. Porto Alegre: Artes Médicas.

Cockrell, S., O'neill, C. \& Stone, J. (2009). Casamento à prova de bebês: como ter uma relação equilibrada, manter a chama acesa e formar uma família feliz. Rio de Janeiro: Sextante.

Costa, M. (1986). Sexualidade na adolescência: dilemas e crescimento. 8.ed. São Paulo: L \& PM Editores.

Del Priore, M. (2005). Histórias do amor no Brasil. São Paulo: Contexto.

Diehl, A. (2002). O homem e a nova mulher: novos padrões sexuais de conjugalidade. In: A. Wagner (Org.). Família em cena. pp. 135158. Petrópolis: Vozes.

Diniz, G. (2009). O casamento contemporâneo em revista. In: T. F. Carneiro (Org.). Casal e família: permanências e rupturas. pp. 135156. São Paulo: Casa do Psicólogo.

Falcke, D., Diehl, J.A. \& Wagner, A. (2002). Satisfação conjugal na atualidade. In: D. Falcke, J. A. Diehl \& A. Wagner (Org.). Família em cena. pp. 172-188. Petrópolis: Vozes.

Feres-Carneiro, T.(2011). Conjugalidades contemporâneas: um estudo sobre os múltiplos arranjos conjugais da atualidade. Rio de Janeiro: Pontifícia Universidade Católica do Rio de Janeiro.

Flick, U. (2009). Introdução á pesquisa qualitativa. 3.ed. Porto Alegre: Artmed / São Paulo: Bookman.

Giddens, A. (1993). A transformação da intimidade: sexualidade, amor e erotismo nas sociedades modernas. São Paulo: UNESP.

Magagnin, C., Korbes, S. M., Hernandez, J. A. E. , Cafruni, S., Rodrigues, M. T. \& Zarpelon, M. (2003). Da conjugalidade à parentalidade: gravidez, ajustamento e satisfação conjugal. Altheia, 17/18, 41-52.

Menezes, C. C., Lopes \& R. C. D. (2007). Relação conjugal na transição para parentalidade: gestação até dezoito meses do bebê. Psico-USF, 12(1), 83-93.

Nichilo, M. (1995). A crise de casal entre pseudo-reciprocidade e emancipação. In: M. Andolfi, M., C. Angelo \& C. Saccu (Orgs.). O casal em crise. São Paulo: Summus.

Pasini, W. (1995). A qualidade dos sentimentos. Rio de Janeiro: Ed. Rocco.

\section{Endereço para correspondência}

Juliana Orrico Viana Vilar 
Programa de Pos-Graduação em Família na Sociedade Contemporânea da Universidade Católica do Salvador. Av. Cardeal da Silva, 205, CEP 40231-902, Salvador - BA, Brasil

Endereço eletrônico: juorrico@gmail.com

\section{Elaine Pedreira Rabinovich}

Programa de Pos-Graduação em Família na Sociedade Contemporânea da Universidade Católica do Salvador. Av. Cardeal da Silva, 205, CEP 40231-902, Salvador - BA, Brasil

Endereço eletrônico: elainepr@brasmail.com.br

Recebido em: 10/05/2012

Reformulado em: 20/11/2013

Aceito para publicação em: 04/12/2013

Acompanhamento do processo editorial: Deise Maria Leal Fernandes Mendes

\section{Notas}

* Psicóloga, Mestre em Família na Sociedade Contemporânea, Bahia

** Psicóloga, Doutorado e Pós-Doutorado pela Universidade de São Paulo.

Professora do Programa de Pós-Graduação em Família na Sociedade

Contemporânea da Universidade Católica do Salvador, Bahia. 